\title{
POLÍTICAS LINGUÍSTICAS E O LUGAR DA LÍNGUA ESPANHOLA NOS INSTITUTOS FEDERAIS
}

\author{
POLÍTICAS LINGÜÍSTICAS Y EL LUGAR DE LA LENGUA ESPAÑOLA EN LOS \\ INSTITUTOS FEDERALES
}

\section{LANGUAGE POLICIES AND PLACE OF SPANISH LANGUAGE IN THE FEDERAL INSTITUTES}

Fernanda TONELLI ${ }^{1}$

RESUMO: Este artigo discute a respeito da (in)visibilidade da língua espanhola enquanto conteúdo curricular na rede básica de ensino brasileira. Desse modo, refletiremos a respeito das políticas linguísticas brasileiras de inserção das línguas estrangeiras na educação básica e, em especial, da língua espanhola. Em seguida, analisaremos como se configura a oferta de língua espanhola nos Institutos Federais de Educação, Ciência e Tecnologia. Para isso, nos basearemos em um questionário aplicado aos professores de língua espanhola dessas instituições. Como resultado, as informações coletadas mostram que nessas instituições é dado um espaço secundário à língua espanhola, resultado de um processo histórico de desoficialização do ensino de línguas na rede básica de educação em nosso país.

PALAVRAS-CHAVE: Políticas linguísticas. Educação básica. Língua espanhola. Institutos Federais.

RESUMEN: En este artículo discutimos acerca de la (in)visibilidad de la lengua española como componente curricular en la red básica de enseñanza en Brasil. De ese modo, tratamos sobre las políticas lingüísticas brasileñas de inserción de las lenguas extranjeras en la educación básica y, en especial, de la lengua española. Luego, analizamos cómo se diseña la oferta de la lengua española en los Institutos Federales de Educación, Ciência y Tecnología. Para eso, nos basamos en un cuestionario aplicado a los profesores de lengua española de esas instituciones. Como resultado, las informaciones analizadas muestran que en esas instituciones se da un espacio secundario a la lengua española, resultado de un proceso histórico de desoficialización de la enseñanza de lenguas en la red básica de educación en el país.

PALABRAS CLAVE: Políticas lingüísticas. Educación básica. Lengua española. Institutos Federales.

ABSTRACT: This article discusses the (in)visibility of the Spanish language as a curricular content in the Brazilian basic education system. In this way, this text reflects

${ }^{1}$ Instituto Federal de Educação, Ciência e Tecnologia de São Paulo (IFSP), Capivari - SP - Brasil. Professora de Língua Espanhola. Doutoranda do Programa de Pós-graduação em Linguística e Língua Portuguesa. ORCID: <http://orcid.org/0000-0003-3354-7558>.E-mail: fertonelli@gmail.com 
about the Brazilian linguistic policies of insertion of foreign languages in basic education, and especially of the Spanish language. Then, we will analyze how to configure the Spanish language offer in Federal Institutes of Education, Science and Technology. To do so, we use the results of a questionnaire applied to Spanish teachers. As a result, the data show that in those schools Spanish occupies a secondary space, and it is a result of a historical process of de-officialization of the teaching of languages in the basic education in the country.

KEYWORDS: Language policy. Basic education. Spanish. Federal Institutes.

\section{Introdução}

Após um pouco mais de uma década da aprovação da Lei 11.161/2005, encontramo-nos diante de um contexto de mudanças profundas na estrutura educacional brasileira. A "Lei do Espanhol”, como é conhecida a Lei mencionada acima, contribuiu para que, em apenas um decênio, a língua espanhola transitasse entre as posições de destaque e de apagamento no ensino de línguas de nível médio. No entanto, embora a Lei possa ser encarada como marco regulatório de legitimação do ensino da língua, o processo de inserção do ensino da língua espanhola nas escolas brasileiras não se deu de forma homogênea durante esse período; tampouco sua institucionalização se restringe à data de sanção da Lei 11.161/2005.

Nesse sentido, buscamos refletir sobre a (in)visibilidade da língua espanhola ao longo da história da educação básica brasileira e, em especial, na atual conjuntura. Para isso, inicialmente, faremos uma breve reflexão a respeito das políticas linguísticas brasileiras de inserção das línguas estrangeiras e, em especial, da língua espanhola, na educação básica, com o intuito de identificar qual é o papel ocupado pelas línguas nos documentos oficiais ao longo dos anos. Para este trabalho, o recorte para análise é de 1931 (data da primeira Lei que versa sobre ensino de línguas estrangeiras no Brasil) até 2016.

No segundo momento, analisaremos como se configura a oferta de língua espanhola nos Institutos Federais de Educação, Ciência e Tecnologia (doravante IFs). A escolha pelos IFs deve-se ao fato de essas instituições serem consideradas referência nacional na educação básica de nível médio. Por meio de um questionário aplicado a um grupo de professores de língua espanhola dos IFs, buscamos situar o lugar do espanhol dentro dessas instituições. 
A seguir, faremos uma breve conceitualização a respeito da noção de Políticas Linguísticas, que orientará este trabalho.

\section{Política linguística: o que é}

Quando nos deparamos com o termo "Política Linguística", inevitavelmente o associamos à ideia de discussões, leis, normatização da língua na sociedade. De fato, esta noção não está equivocada, já que o termo "política" evoca a ideia de organização, representação e a este termo junta-se o linguístico, de caráter social e histórico.

Enquanto área de estudos, há uma variedade de definições para Política Linguística, que abordam diferentes características e perspectivas teóricas. Para este trabalho, tomaremos como base o conceito de Calvet (2007, p. 11), o qual define política linguística como decisões relacionadas a língua e sociedade. Essas escolhas são tomadas de forma consciente, atingem a sociedade em âmbito nacional e estão tradicionalmente ligadas a práticas de caráter estatal-legislativo. Embora esse autor tenha focado, em sua obra seminal, questões relacionadas estritamente a idiomas nacionais, também podemos considerar o conceito e o estudo dessa disciplina para refletir sobre as línguas que não estão na posição de língua oficial do país, mas fazem parte da cultura escolar dessa sociedade, como o caso do ensino da língua espanhola no Brasil.

A respeito do status da Política Linguística, podemos afirmar, em comparação à Linguística:

A primeira [Linguística] sempre alardeou sua suposta neutralidade política, ao passo que a segunda [Política Linguística] assume, em sua própria nomenclatura, seu caráter político. A primeira sempre fez questão de frisar o caráter descritivo de suas investigações, enquanto que a segunda é escancaradamente prescritiva e interventora. A primeira concentra seus esforços quase exclusivamente no oral, ao passo que a segunda se dirige à escrita, reconhecendo que qualquer repercussão na forma oral da língua ocorre como consequência. (RAJAGOPALAN, 2008, p. 135)

Calvet (2007) nos mostra que a Política Linguística surgiu como área de estudos na década de 1960, juntamente com os estudos da Sociolinguística. Nesse momento, o linguista estadunidense Einar Haugen realiza um estudo sobre a intervenção do Estado norueguês na língua nacional de modo a combater a dominação dinamarquesa. A partir de então, outros teóricos se debruçaram sobre questões relacionadas à língua e ao 
planejamento estatal. Surge também o termo "planejamento linguístico", que pode ser entendido como implementação, essa realizada por meio de escolhas que efetivem as políticas linguísticas definidas. Desse modo, o planejamento linguístico depende de uma política linguística, mas o contrário não. Isso porque, segundo Haugen (apud CALVET, 2007), na etapa de planejamento linguístico estão desenvolvidos os "procedimentos de decisão" ou as etapas de definição da problemática, as decisões, as alternativas, a avaliação e a aplicação.

O conceito de planejamento linguístico foi posteriormente se desdobrando e se dividindo em diferentes níveis, como planejamento de corpus (quando o foco está na elaboração de elementos linguísticos para uma língua), planejamento de status (na elevação de uma língua a status nacional, por exemplo, como no caso do reconhecimento do guarani como língua nacional do Paraguai em 2011), o planejamento de usos (para a divulgação e uso da língua), o planejamento de prestígio (avaliação da língua) e o planejamento das forma de aquisição (que diz respeito ao ensino e aprendizagem de línguas). É sobre este último item que nos interessa discutir neste momento.

Se considerarmos que, na sociedade, toda a prática de ensino e aprendizagem realizada em instituições de ensino é fruto de decisões tomadas, seja a partir de leis, acordos ou outras formas de organização e regulação, o que hoje temos no campo do ensino/aprendizagem é, de acordo com o linguista Rajagopalan, manifestação da política linguística (SILVA; SANTOS; JUSTINA, 2011/02).

Importante considerar que, embora a definição de Política Linguística como um campo de estudos da Linguística seja algo recente, as Políticas Linguísticas em si vêm sendo praticadas desde momentos remotos da civilização. No caso do Brasil, por exemplo, podemos considerar as instruções de Caminha em sua Carta como uma Política Linguística, dado que nesse documento é sugerido que os jesuítas aprendam a língua local e não o contrário, de modo a catequizar os indígenas.

Como forma de refletir a respeito da Política Linguística no ensino e aprendizagem, tomaremos como base o atual contexto de ensino de línguas estrangeiras no Brasil, no qual se insere a problemática da oferta de língua espanhola nas escolas brasileiras. Para isso, tomaremos como base a leitura de Picanço (2003) e de Rodrigues (2010). 


\section{Ensino de línguas no Brasil: do Ontem Moderno aos dias de Hoje}

Ao traçarmos um cronograma histórico a respeito do ensino de línguas no Brasil, consideraremos como ponto de partida o ano de 1931, o Ontem Moderno², com a Reforma Francisco de Campos $^{3}$. Na ocasião, o ensino secundário foi distribuído em 5 anos e tinha o francês, o inglês e o latim como disciplinas obrigatórias e o alemão como língua optativa.

Na década de 1940, a Política Linguística da Era Vargas preconizava que a educação deveria estar a serviço de toda a nação, de modo a atender à realidade política, econômica e moral do país. Como planejamento linguístico fruto dessa política, temos a Reforma Capanema, em 1942, com a reformulação do ensino secundário, a qual previa a ampliação do ensino de línguas estrangeiras sob o argumento da importância dos estudos da língua universal, com vantagem ao ensino de francês e inglês. Importante destacar que, embora mínimo, instituiu-se o ensino da língua espanhola (com carga horária de duas horas semanais).

A inserção do espanhol na educação básica, embora possa ser reconhecida como um avanço na história da oferta dessa língua, é resultado de uma política de silenciamento realizada por parte do Estado às línguas consideradas "inimigas" na época. Desse modo, o espanhol, enquanto componente curricular oficial, ocupa uma posição de segundo plano dentre as línguas estrangeiras oferecidas. Isso se confirma pelo fato dessa língua compor somente o quadro de disciplinas do primeiro ano da escola secundária, sendo a disciplina com menor atribuição de aulas entre as línguas estrangeiras (RODRIGUES, 2010, p. 73).

A respeito da oficialização da oferta da língua espanhola, Freitas e Barreto afirmam, baseadas em Picanço (2003):

a substituição do alemão pelo espanhol se explica não apenas pelo fato
de aquela ser a língua do inimigo na Guerra Mundial, mas também
como uma tentativa de sufocar as colônias alemãs do sul do país que
insistiam em manter a língua dos seus antepassados e em não adotar o
português. A opção pelo espanhol se deu em função de que o inglês e o

${ }^{2}$ Almeida Filho (2003) organiza a cronologia sobre o ensino de línguas no Brasil de acordo com dois grandes períodos: o Período Ontem - composto pelos períodos Ontem Longínquo (1500-1808), Ontem Próximo (1808-1930) e Ontem Moderno (1931-1978) - e o Período Hoje - de 1978 aos dias atuais. É a partir do período Ontem Moderno que nos debruçamos neste trabalho.

${ }^{3}$ O nome da reforma é uma homenagem ao Ministro da Educação e Saúde Pública responsável pela primeira legislação nacional para normalizar a educação em nível secundário e superior (RODRIGUES, 2010, p. 63). 
francês já faziam parte do currículo e o italiano padecia dos mesmos problemas do alemão. Além disso, o espanhol era língua de grandes clássicos da literatura e, naquele momento, não havia a possibilidade de se incluir nas escolas do nosso país qualquer outra língua estrangeira além das cinco já mencionadas. (FREITAS; BARRETO, 2007, p. 5859)

Em 1961, as Leis de Diretrizes e Bases da Educação representam um retrocesso para o ensino de língua estrangeiras de um modo geral, dado que essas deixam de compor a grade de disciplinas obrigatórias, sob a justificativa de que seu ensino é pouco eficaz nas escolas. Nesse sentido, Rodrigues afirma:

Até a legislação de 1942, o Estado se encarregava de fazer constar tanto a obrigatoriedade quanto a quantidade e especificação das línguas que comporiam a grade curricular do sistema educacional brasileiro - expressos pela lista de disciplina que fariam parte dos diferentes níveis de ensino. A LDB de 1961, no entanto, opera no sentido contrário ao dessa memória já constituída, produzindo o apagamento das línguas e dando início ao que interpretamos como um processo de desoficialização de ensino de línguas no contexto escolar. (RODRIGUES, 2010, p. 298)

O ensino de língua estrangeira só volta a integrar o núcleo de disciplinas obrigatórias a partir de 1976 e se torna obrigatório no ensino fundamental somente no fim do século, com a Lei de Diretrizes e Bases da Educação Nacional (LDB) de 1996. Nesse segundo documento, se estabelece que será incluída uma língua estrangeira como disciplina obrigatória (cuja escolha deve ser feita pela comunidade escolar), além do oferecimento de um segundo componente curricular de língua estrangeira, que poderá ser ministrado em caráter optativo de acordo com a disponibilidade da instituição. Desse modo, a LBD de 1996 é marcada pela indeterminação do ensino de línguas na educação básica (RODRIGUES, 2010), já que não há qualquer menção à(s) língua(s) que deve(m) ser oferecidas e quais atores, de fato, são responsáveis pela sua escolha. Isso contribuiu para a hegemonia da língua inglesa nas escolas, com casos isolados de oferecimento de uma segunda disciplina de língua estrangeira até final da década de 2010.

Concomitantemente a esse processo, temos o estreitamento das relações comerciais entre o Brasil e alguns países da América Latina, sobretudo pela criação do Mercosul (Mercado Comum do Sul), o que gera uma nova dinâmica de integração entre os países desse bloco econômico e acende o discurso de reencontro entre as nações latino-americanas. Além disso, há o interesse por parte do governo brasileiro em 
(re)estabelecer relações com a Espanha, a qual tem um importante mercado editorial (JAEGER, 2009), além desse ser um dos maiores investidores do Brasil. Como parte desse novo contexto, em 2005, foi aprovada a Lei 11.161/2005, que obriga o oferecimento da língua espanhola nas escolas de nível médio no país, com matrícula facultativa ao aluno.

Rodrigues (2016) redimensiona a Lei 11.161/2005 ao afirmar que não se trata da "Lei do Espanhol", exclusivamente, mas de uma lei da ampliação da oferta de língua estrangeiras na escola a partir do momento em que ela obriga a oferta da língua espanhola no Ensino Médio. Assim, a Lei fez cumprir a lacuna tida até então no ensino da segunda língua estrangeira que era proposta pela LDB de 1996.

Importante considerar que, embora houvesse uma Lei que obrigasse o oferecimento do espanhol nos currículos plenos do ensino médio, na prática, a normativa vinha sendo descumprida devido a diversos fatores, dentre os quais podemos citar o déficit de professores formados para ministrar a disciplina, a falta de concursos para contratação desses profissionais e a desvalorização das línguas estrangeiras como um todo dentro do cenário escolar.

Passados mais de 20 anos desde a sanção da LBD de 1996 e uma década da aprovação da Lei 11.161, deparamo-nos em 2016 com a proposta de "Reforma do Ensino Médio", tal como é cunhada pelo atual governo. Trata-se da Medida Provisória n 746 de 2016, que prevê um processo de reformulação da educação. Um dos aspectos mais significativos dessa Medida Provisória é a revogação da Lei 11.161, retirando, dessa forma, a obrigatoriedade da oferta da língua espanhola para o Ensino Médio. No entanto, uma questão se faz pertinente: diante de todos os percalços relacionados à oficialização da língua espanhola na educação básica ao longo dos anos, qual posição ela ocupa nas instituições de educação básica?

Para responder a essa pergunta, nos debruçamos sobre o contexto de ensino dos Institutos Federais de Educação, Ciência e Tecnologia. A seguir, apresentamos uma breve descrição sobre essa instituição de ensino.

\section{Os Institutos Federais de Educação, Ciência e Tecnologia: Ilhas de excelência em meio ao caos ${ }^{4}$}

${ }^{4} \mathrm{O}$ título do item é uma referência ao texto jornalístico publicado no site de notícias El país em 12 de dezembro de 2016, o qual informa a respeito do alto desempenho dos Institutos Federais na avaliação de Programa Internacional de Avaliação de Estudantes de 2015 (PISA) 
A rede federal de ensino profissional no Brasil remonta ao início do Século XX, tendo incorporado, desde então, diferentes propostas e instituições educacionais do país. Em 2008, surgem os Institutos Federais de Educação, Ciência e Tecnologia, criados por meio do Projeto de Lei 11.892/2008 e sancionado pelo então presidente da República Luiz Inácio Lula da Silva. Desde então, são contabilizados 38 Institutos Federais espalhados pelo Brasil com aproximadamente 650 campi em funcionamento ${ }^{5}$. Os IFs têm como foco a oferta de educação profissional e tecnológica em diferentes níveis, incluindo a educação básica de nível médio. Como finalidade e característica dos IFs, a legislação vigente determina que essas instituições atuem como centros de excelência e referência na oferta do ensino de ciências, tanto gerais como aplicadas, em seus diferentes níveis e modalidades (BRASIL, 2008, art. $6^{\circ}$ ).

Com um novo modelo institucional, os IFs vêm construindo uma identidade educacional marcada pela qualidade, e um dos resultados desse trabalho são os altos índices em avaliações nacionais e internacionais. Como fatores determinantes para a qualidade no ensino, podemos citar a infraestrutura, gestão democrática e autônoma dos institutos e equipe administrativa e docente de qualidade. Desse modo, podemos considerar os IFs como instituições de referência dentro do cenário nacional de ensino.

Ainda que não tenhamos acesso a dados que tratem do quadro de professores de língua espanhola em todos os IFs, podemos afirmar que, de modo geral, as instituições buscaram cumprir a Lei 11.161 que trata da obrigatoriedade do espanhol no Ensino Médio, visto que, até 2016, foram abertos com certa frequência concursos públicos em vários estados do país.

Neste trabalho, contamos com a contribuição de docentes da área de língua espanhola de diferentes IFs, que responderam um questionário sobre a situação da língua espanhola enquanto componente curricular em cursos oferecidos em seus campi. Essa coleta foi feita em 2017, quando a "Lei do Espanhol" ainda não havia sido revogada pela Medida Provisória $\mathrm{n}^{\mathrm{o}}$ 746. As informações coletadas estão presentes no item a seguir.

\section{A língua espanhola nos Institutos Federais}

O levantamento a respeito da oferta de língua espanhola nos campi dos Institutos Federais contou com a contribuição de professores concursados para a área de espanhol

${ }^{5}$ Retirado de: 〈http://redefederal.mec.gov.br/expansao-da-rede-federal >. Acesso em: 24 jan. 2018. 
nessas instituições. Ao todo, foram 26 participantes de 7 estados diferentes, distribuídos pelas regiões Sul, Sudeste, Nordeste e Centro-oeste.

Desses 26 profissionais, $17(65,4 \%)$ estão habilitados a dar aulas em sua instituição tanto de português como de espanhol por especificação da vaga que ocupam, ao passo que os outros 9 (isto é, $34,6 \%$ ) ocupam somente a cadeira de língua espanhola, devido ao fato de seu concurso público ter sido somente para essa área.

Por meio desse dado, podemos observar que a maior parte das instituições opta por exigir um profissional da área de Letras que possa atuar tanto no ensino da língua materna quanto da língua estrangeira. A dupla habilitação (e até tripla, em casos que incluem o inglês) visa fazer com que o professor de línguas complemente sua carga horária dentro da instituição com aulas de Português, caso não haja aulas de línguas estrangeiras suficientes a serem-lhe atribuídas. Também a condição contrária é identificada: esse profissional, não tendo aulas suficientes de Português para compor sua carga horária, a complementa com aulas de língua(s) estrangeira(s).

A contratação de professores de espanhol condicionada a sua possibilidade em ministrar aulas de português explicita o papel secundário dado à língua estrangeira nos IFs, o que é sentido pelo próprio corpo docente, conforme opinião de um participante da pesquisa sobre sua instituição:

$\mathrm{Na}$ instituição como um todo tampouco há muito apoio, tanto que não permitem que se faça concurso apenas de espanhol ou apenas de inglês, sempre tem que ser duplo (português $+L E$ ).

No período em que foi aplicado o questionário, $88,5 \%$ dos professores respondentes afirmaram estar atuando no ensino de espanhol. Desse montante, $42,8 \%$ se dedicam somente às aulas de língua espanhola, enquanto os outros se dividem entre o ensino de duas ou três línguas, conforme indicado na tabela a seguir:

Tabela 01: Reposta para a pergunta "Atualmente, em seu campus, você atua como professor(a) em mais de uma área?"

Atualmente, em seu campus, você atua como professor(a) em mais de uma área?

Resposta

Porcentagem 


\begin{tabular}{l|l}
\hline Não, sou apenas professor(a) de espanhol & $42,8 \%$ \\
\hline Sim, sou professor(a) de português e espanhol & $47,6 \%$ \\
\hline Sim, sou professor(a) de inglês e espanhol & $4,7 \%$ \\
\hline Sim, sou professor(a) de português, inglês e espanhol & $4,7 \%$ \\
\hline
\end{tabular}

Fonte: material próprio

Já os $11,5 \%$ de participantes que declararam não estar atuando na área de espanhol no momento da pesquisa, atribuíram isso ao papel hegemônico da língua inglesa, ao fato do seu campus estar em funcionamento "provisório", inaugurado há pouco tempo e também a outras demandas profissionais que não podem ser conciliadas com atribuições de aula de espanhol. Como exemplo de outras demandas, foi citado o exercício em cargos de gerência e coordenadoria e também a escassez de professores no campus, que faz com que o profissional com dupla habilitação tenha que se dedicar prioritariamente à língua materna (que é obrigatória) em detrimento da estrangeira, optativa.

Também foi questionado aos participantes se a língua espanhola era componente curricular de algum curso superior ou em cursos de extensão em seu campus. Apenas 26,9\% afirmaram que o espanhol compõe carga horária de algum curso superior em seu campus, o que revela a desvalorização da língua espanhola em nível acadêmico nos IFs. Por outro lado, cerca da metade das instituições pesquisadas $(53,8 \%)$ oferecem cursos à comunidade em caráter de extensão. Essa discrepância na oferta de língua espanhola em cursos superiores e em cursos de extensão evidencia o que Rodrigues (2010) identifica como disjunção entre a língua estrangeira da escola e a língua estrangeira dos cursos livres, com prioridade para a oferta da segunda opção.

Isso se reflete mais claramente na educação básica, quando observamos os dados sobre a oferta da língua espanhola nos cursos de Ensino Médio que compõem esses campi. De acordo com os participantes, 57,7\% afirmaram que seu campus oferece língua espanhola de acordo com disposto na Lei 11.161, isto é, sendo de oferta obrigatória, mas de matrícula facultativa ao aluno. Somando-se à porcentagem de campi 
que têm o espanhol como componente curricular regular no Ensino Médio (compondo igualmente o quadro de disciplinas obrigatórias juntamente com o português e matemática, por exemplo), chegamos à porcentagem de $73,1 \%$ dos campi analisados. Esse é um valor expressivo, o que demonstra haver demanda por profissionais da área de língua espanhola dentro dos IFs. Refletindo a respeito da escassez de oferta dessa língua em outros níveis de ensino, podemos concluir que, caso houvesse reconhecimento e apoio por parte das instituições à oferta da língua espanhola em outros níveis de educação, provavelmente não seria necessária a contratação de profissionais "poli-habilitados", que se dividem em duas e até três áreas de ensino. Isso porque esses professores conseguiriam completar sua carga horária semanal de atividades com aulas de língua espanhola, apenas.

Importante ponderar que, como um modelo de gestão, os IFs são geridos de forma autônoma e democrática. Isso implica considerar que cada Instituto Federal e, mais especificamente, cada campus tem a liberdade (dentro dos parâmetros estabelecidos pelo MEC) para elaborar a grade curricular de seus cursos de acordo com as especificidades do seu contexto de ensino. No entanto, embora os IFs sejam instituições que gozam de certa liberdade para organizar seu currículo, verificamos que é significativo o número de professores que não se sentem apoiados pelos colegas de trabalho e/ou coordenação quanto à consolidação da área de espanhol em seu campus. Dos participantes que responderam o questionário, 46,1\% consideram receber apoio por parte de colegas e instituição, 15,5\% afirmam ter pouco apoio, 34,6\% declaram não ter nenhum tipo de apoio e 3,8\% não souberam opinar. Entre os que declaram não receber qualquer tipo de apoio, foi recorrente relatos sobre a falta de compromisso em relação à Lei e o descaso por parte de colegas e coordenação, como podemos verificar nas respostas selecionadas a seguir:

Dentro do campus, não vejo nenhuma motivação por parte de Coordenadores, Gerências, nem Direção. $O$ descaso ficou explícito quando, no segundo semestre de 2016, sugeri a inserção da disciplina técnica "Espanhol para Negócios" como componente do Integrado em Administração (que estava em processo de criação) e houve uma veemente defesa contrária a existência da disciplina.

Entre os colegas do núcleo comum, parece haver maior apoio ao ensino do idioma; já para os colegas das áreas técnicas, esse apoio não é claro. 
O apoio existe por parte da nova gestão, tanto que houve concurso para a área de línguas, mas antes não existia e por parte da área técnica não há apoio algum, eles consideram que língua estrangeira tem que ser aprendida em escola de idioma.

Os relatos a respeito do descaso por parte de colegas, em especial aqueles que pertencem às áreas específicas profissionalizantes dos cursos, evidenciam a visão cristalizada de que há dois níveis de disciplinas: de um lado, aquelas que são de fato importantes à formação profissional do aluno e, por isso, adquirem o status oficial, obrigatório; do outro, as disciplinas de línguas, de caráter optativo e secundário e que, segundo alguns, deveria restringir-se a ser ensinada em escola de idioma. De certo modo, a "Lei do Espanhol" contribuiu para essa cisão, dado que ela claramente desobriga o aluno de cursar a disciplina de língua espanhola, colocando-a em outro patamar da grade curricular:

\begin{abstract}
A Lei 11161/2005 incorpora essa lógica, assume essa memória e 'obriga a oferta', mas mantém como 'optativa a matrícula', legitimando um imaginário segundo o qual as línguas estrangeiras podem ser facultativas ao aluno, podem ser um componente extracurricular, podem até mesmo ser ensinadas fora da escola, ou seja, totalmente desvinculadas dos demais conteúdos que compõem a grade curricular. (RODRIGUES, 2010, p. 299)
\end{abstract}

Desse modo, a Lei, ainda que tenha oportunizado a presença do profissional de língua espanhola nas instituições de Ensino Médio, não garantiu que a disciplina obtivesse visibilidade junto às demais matérias do currículo escolar.

Por outro lado, também é importante salientar as referências feitas ao apoio por parte de colegas e administração escolar na promoção do espanhol nas instituições analisadas. Dos participantes da pesquisa, $61 \%$ afirmaram que a equipe escolar apoiava (em diferentes graus) a oferta de língua espanhola na escola. A seguir, destacamos algumas respostas à pergunta que trata da dinâmica de oferta da língua nesses campi ("Você considera que há apoio da Coordenação e dos colegas professores em consolidar a área de língua espanhola dentro do seu campus? E na sua instituição como um todo?"):

De modo geral, sim, ainda que a disciplina de língua espanhola seja oferecida em horário fora da grade (almoço ou fim de tarde).

Minhas colegas de português-inglês, às vezes, assumem mais aulas para que eu possa oferecer espanhol na condição de 
curso de extensão. Isso não significa que eu fique com menos aulas; significa que eu não extrapolo em muito a minha carga didática.

Sim, principalmente pela visibilidade do campus na cidade ao ofertar o idioma.

A situação em meu campus é exceção, devido ao fato de que houve ampla mobilização dos docentes, $e$ apoio da coordenação, para que o espanhol fosse oferecido a todos os alunos do Médio Integrado.

Todo o campus lamentou e muito as mudanças feitas sob o nome de "Reforma do EM". A revogação da Lei 11,161/2005 representa um grande retrocesso.

Identificamos, nas respostas dos participantes, situações em que o apoio dos colegas da instituição está condicionado ao esforço do próprio docente de espanhol na promoção da língua dentro e fora do campus. Isso implica no trabalho constante de divulgação de cursos para a comunidade, comprometimento de uma maior carga de trabalho para poder oferecer a língua espanhola e disponibilidade para trabalhar em horários alternativos. Nesse sentido, o valor agregado a essa língua é de complemento, um "extra" que a instituição oferece para além do ensino "oficial". Isso se confirma quando um dos participantes declara que as disciplinas de espanhol estão no horário do almoço ou fim da tarde, isto é, no contraturno de aulas. Assim, reafirma-se o imaginário de que o lugar da língua estrangeira não é o mesmo das outras disciplinas, reforçando o caráter optativo e secundário legado às línguas estrangeiras.

É importante considerar, por fim, que há também referências à conscientização e apoio por parte da Coordenação e corpo docente das instituições analisadas, por meio de relatos de mobilização da equipe escolar e solidariedade à área de língua espanhola, sendo esse posicionamento fundamental para a manutenção da disciplina na instituição.

\section{Considerações finais}

Por meio deste trabalho, observamos que a sanção de uma Lei não significa seu cumprimento pleno. Isso pode ser verificado pelas respostas ao questionário aplicado aos professores de língua espanhola de diferentes campi de Institutos Federais espalhados pelo Brasil. Percebemos que, passados mais de dez anos da aprovação da "Lei do Espanhol”, ainda há instituições que não se adequaram às exigências da Lei. 
Esta pesquisa, embora modesta, oferece subsídios para afirmarmos que um dos aspectos que mais contribuem para o descumprimento da Lei é a desvalorização que a língua estrangeira adquiriu dentro do ambiente escolar. Isso é fruto de uma política linguística que, desde a publicação da LDB de 1961, busca desoficializar o ensino de língua estrangeira (RODRIGUES, 2010), no sentido de tirar do Estado a obrigatoriedade em oferecer línguas no ensino básico regular a todos os estudantes.

Logo, não é de se espantar atualmente o baixo rendimento dos estudantes brasileiros em avaliações internacionais de línguas estrangeiras, como o inglês, e a necessidade de programas complementares de formação em língua estrangeira a universitários, como é o caso do Idioma sem Fronteiras. Um Estado que não tem como prioridade o ensino de línguas dentro das escolas, torna-se refém de programas paliativos.

Como pudemos ver neste trabalho, ainda que a Lei 11.161/2005 tivesse recolocado a língua estrangeira em posição de destaque, em dados momentos ela dificultou o processo de valorização do espanhol, na medida em que instituiu o caráter facultativo ao seu estudo. Como resultado, vemos que, mesmo em instituições de reconhecida qualidade de ensino como é o caso dos Institutos Federais, ainda paira o imaginário de que à língua estrangeira cabe a posição secundária, quando não seu apagamento. E o aspecto mais alarmante é que a invisibilidade da língua acontecia mesmo quando a Lei ainda estava em vigor. Desse modo, não é difícil prever o cenário negativo do ensino de língua espanhola nos próximos anos.

AGRADECIMENTOS: Agradeço gentilmente a colaboração dos professores que puderam contribuir respondendo as questões para esta pesquisa.

\section{REFERÊNCIAS}

ALMEIDA FILHO, J. C. P. de. Ontem e hoje no ensino de línguas no Brasil. In: STEVENS, C. M. T.; CAVALCANTI, M. J. (orgs.). Caminhos e colheita: ensino e pesquisa na área de inglês no Brasil. Brasília: Editora Universidade de Brasília, 2003.

BRASIL. Lei $\mathbf{N}^{\circ}$ 11.892, de 29 de dezembro de 2008. Disponível em: <http://www.planalto.gov.br/ccivil_03/_ato2007-2010/2008/lei/111892.htm>. Acesso em: 09 jan. 2017. 
BRASIL. Lei $\mathbf{N}^{\mathbf{0}}$ 11.161, de 05 de agosto de 2005. Disponível em: <http://www.planalto.gov.br/ccivil_03/_ato2004-2006/2005/lei/111161.htm>. Acesso em: 09 jan. 2017.

CALVET, J. As políticas linguísticas. São Paulo: Parábola Editorial: IPOL, 2007.

FREITAS, L. M. A. de.; BARRETO, T. A. Construindo uma história: a APEERJ e o ensino de espanhol no Brasil. In: Anuario brasileño de estudios hispánicos, 2007, p. 65-69.

JAEGER, D. Língua espanhola nas escolas brasileiras, interação e política linguística: reflexões em torno da aprovação da Lei 11161/15. Revista espaço acadêmico, n. 97, jun. 2009.

RAJAGOPALAN, K. As políticas linguísticas. DELTA, São Paulo, v. 24, n. 1, p. 135 139, 2008.

RODRIGUES, F. C. dos S. Língua viva, letra morta: obrigatoriedade e ensino de espanhol no arquivo jurídico e legislativo brasileiro. Tese (Doutorado em Língua Espanhola), Universidade de São Paulo, 2010.

RODRIGUES, F. C. dos S. Vão as leis onde querem os reis: antecedentes da Lei no 11.161/2005. In: BARROS, C. (org.). Dez anos da "Lei do Espanhol" (2005-2015). Belo Horizonte: FALE/UFMG, 2016.

SILVA, K. A.; SANTOS, L. I. S.; JUSTINA, O. D. Entrevista com Kanavillil Rajagopalan: ponderações sobre linguística aplicada, política linguística e ensinoaprendizagem. Revista de Letras Norte@mentos - Revista de Estudos Linguísticos e Literários. Edição 08 - Estudos Linguísticos, 2011/02.

\section{Como referenciar este artigo}

TONELLI, Fernanda. Políticas linguísticas e o lugar da língua espanhola nos Institutos Federais. Rev. EntreLínguas, Araraquara, v.4, n.1, p. 43-57, jan./jun., 2018. E-ISSN: 2447-3529. DOI: 10.29051/rel.v4.n1.2018.10979

Submetido em: 30/01/2018

Revisões requeridas: 14/03/2018

Aprovado em: 12/04/2018 